\title{
Application and Research of Photovoltaic New Energy in Electrical Energy Conservation
}

\author{
Bin Tan*, Hualong Li, Yafeng Jiang, Long Zhai \\ Changqing Engineering Design Co., LTD., Xi'an 710018, Shaanxi Province, China
}

*Corresponding author: Bin Tan, 3432413925@qq.com

\begin{abstract}
At present, the increasing consumption of electrical energy is accompanied by the increasing pressure on natural environment, excessive discharge of waste gas, and accelerated rate of global warming. Photovoltaic new energy plays an important role in reducing costs and improving resource utilization. The leading power industries should come up with new designs of equipment that is in line with the green concept, improve the utilization of photovoltaic energy, and realize sustainable economic development. In view of this, this paper mainly analyzes the application of photovoltaic new energy in electrical energy conservation.
\end{abstract}

Keywords: Electrical energy conservation; Photovoltaic new energy; Application

Publication date: September 2021; Online publication: September 30, 2021

\section{Introduction}

The imbalance of power development and energy shortage are important problems facing China. The new round of energy revolution also puts forward stricter requirements for the development of the energy industry. Effectively developing new energy and electrical energy conservation measures form an important part of the development direction of comprehensive energy development and utilization. With the improvement of technology, the conditions for the application and promotion of large-scale new energy have been met, and relevant enterprises should actively develop and utilize new energy resource. At the same time, we should strengthen the awareness of electrical energy conservation from the perspective of the whole life cycle, execute energy-saving measures, reduce energy consumption, improve the economic and social benefits of enterprises, and promote the green and healthy development of China's energy market.

\section{Principle of photovoltaic new energy power generation technology}

The application of photovoltaic new energy is mainly used for power generation. It absorbs light energy through solar panels and converts light energy into electrical energy in its internal system in a process called photovoltaic power generation, and then the inverter transfers the electric energy from direct to generate alternating current, so as to facilitate people's life and use. Through thermodynamic research, photovoltaic power generation has a theoretical power generation rate of $80 \%$, suggesting the great potential in technical development. Photovoltaic power generation uses solar panels to absorb light energy for power generation. In the whole power generation process, it is converted inside the panel. Machinery and fuel are not involved, so it will not contribute to noise pollution and waste gas pollution.

Photovoltaic new energy power generation technology adopts crystalline silicon materials, and the service life of crystalline silicon solar cells is long, up to 25-30 years, and the structure of polysilicon photovoltaic modules is relatively simple, which is convenient for installation, transportation and module expansion, so as to shorten the periodic time of photovoltaic power generation system construction. 
3. Application and optimization strategy of photovoltaic new energy in electrical energy conservation 3.1. Application mode of photovoltaic new energy

\subsubsection{Solar cell array}

When light is present, the battery will react and absorb a certain amount of light energy. By observing both ends of the battery, different charge accumulation forms a photovoltage, that is, the photovoltaic effect. Based on this effect, electromotive force is formed at both ends of the battery, promoting the conversion of light energy into electrical energy. Thus, this is similar to an energy converter. Generally, solar cells can be divided into three types: the first is silicon cells, the second is single crystalline silicon solar cell, and the third is polycrystalline silicon solar cells and amorphous silicon solar cells ${ }^{[1]}$.

\subsubsection{Controller}

Considering the whole system as a unity, through the use of the controller, it can carry out process control, give play to the positive impact on the battery at the same time, and provide charging protection and overdischarge protection. When it is in a relatively high temperature environment, the equipment can also compensate for high temperature.

\subsubsection{Inverter}

Solar cells and batteries belong to direct current power supply. If they serve as alternating current loads, the inverter will convert direct current to make them necessary equipment for alternating current. Based on the operation mode, the equipment can be divided into two categories: one is independent operation inverter and the other is grid connected inverter. When selecting the inverter model, various factors must be comprehensively considered, such as power consumption and material, so as to ensure safety.

\subsection{Optimization strategy}

\subsubsection{Optimization wire rod}

The application of photovoltaic new energy in electrical energy conservation is analyzed from the perspective of power transmission path and the improvement of power application efficiency. The optimization of wire rod is the main optimization strategy for the application of photovoltaic new energy in electrical energy conservation. In the specific implementation, the construction unit shall select the wire based on the principle of high-power conductivity and high conductivity. While laying line materials, the feeder circuit design shall be minimized to reduce the undesirable line loss caused by over-complicated circuit design.

\subsubsection{Reasonable planning and design of photovoltaic power network}

Photovoltaic new energy is applied to electrical energy conservation projects. From the perspective of energy-saving effect control, in order to reasonably improve the power application efficiency of photovoltaic new energy, it is necessary to ensure the stable power consumption by users, and reasonably plan and design the photovoltaic power network. That is the main optimization strategy in the application of photovoltaic new energy technology ${ }^{[2]}$. In the specific implementation, the designers should implement the planning and design of photovoltaic power network from the aspects of voltage drop design, power supply range planning and design, power supply quantity design and control.

\subsubsection{Reasonable selection of electrical equipment}

Photovoltaic new energy is applied in electric energy conservation. Analyzing from the photovoltaic new energy capacity, voltage, and power supply stability, it is effective to execute the application effect of photovoltaic new energy, and at the same time to reduce the micro network fluctuation caused by electrical 
equipment damage. Planners and designers should pay attention to the reasonable selection of transformers and electrical appliances ${ }^{[3]}$.

\subsubsection{Strengthening the installation and maintenance of photovoltaic new energy devices}

In the electrical energy conservation project, the wide application of photovoltaic new energy and the implementation of device installation and maintenance can improve the effect of technology application. At the same time, it is conducive to the later application of technology so that its safety can be effectively controlled. When installing the device, the staff needs to check the site environment in detail and determine device quality in order to control work quality.

\section{Conclusion}

Power energy is closely related to human life and production. Energy strategy has always been an important part of national strategy. With the development of economy and the rapid advancement of industrialization and urbanization, the demand and quality requirements for electrical energy are also increasing. In recent years, problems such as insufficient energy supply, unbalanced energy development structure and the demand of a new round of energy revolution have attracted increasing attention. Therefore, we should pay attention to the sustainable development of electrical energy, vigorously develop renewable energy, improve energy-saving ideas and means, actively devise and discover new energy sources, and vigorously reduce energy expenditure, so as to ensure the balance in the production and expenditure of electrical energy.

\section{Disclosure statement}

The authors declare no conflict of interest.

\section{References}

[1] Sun RJ, 2020, Research on the Application of Photovoltaic New Energy in Electrical Energy Conservation. Technology Innovation and Application, 2020(25): 168-169.

[2] Chen DH, 2020, Analysis on the Application of Photovoltaic New Energy in Electrical Energy Conservation. Technology Wind, 2020(10): 14.

[3] Hua CJ, 2019, Application of Photovoltaic New Energy in Electrical Energy Conservation. Electric Engineering, 2019(24): 130-131. 